\title{
PENGARUH DISIPLIN KERJA TERHADAP KINERJA KARYAWAN PADA PT ISS INDONESIA AREA WTC 3 SUDIRMAN
}

\author{
1Uswatun Chasanah, ${ }^{2 *}$ Feb Amni Hayati, ${ }^{3}$ Wiwit Safitri \\ Universitas Pamulang, Tangerang Selatan, Indonesia

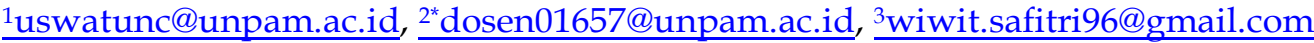

\begin{abstract}
Abstrak
Tujuan penelitian ini adalah untuk mengetahui pengaruh disiplin kerja terhadap kinerja karyawan pada PT. ISS Indonesia AREA WTC 3 SUDIRMAN. Teknik sampling yang digunakan adalah sampling jenuh menggunakan dengan sampel sebanyak 50 responden. Analisis data menggunakanuji validitas, uji reliabilitas, uji asumsi klasik, analisis regresi, analisis koefisien korelasi, analisis koefisien determinasi dan uji hipotesis.Hasil penelitian ini adalah Disiplin berpengaruh signifikan terhadap kinerja karyawan dengan persamaanregresi $Y=15,102+0,625 X_{1}$, nilai korelasi sebesar 0,661 artinya kedua variabel memiliki tingkat hubungan yang kuat dengan koefisien determinasi sebesar $43,8 \%$. Uji hipotesis diperoleh $\mathrm{t}$ hitung $>\mathrm{t}$ tabel atau $(6,111>2,011)$. Dengan demikian $\mathrm{H} 0$ ditolak dan $\mathrm{H} 1$ diterima artinya terdapat pengaruh signifikan antara disiplin terhadap kinerja karyawan.
\end{abstract}

Kata Kunci: Disiplin, Kinerja Karyawan

\section{Abstract}

The purpose of this study was to determine the effect of work discipline and work motivation on employee performance at PT. ISS Indonesia WTC 3 Sudirman area, both partially and simultaneously. The method used is an associative method. The sampling technique used is saturation sampling using a sample of 50 respondents.Data analysis uses validity test, reliability test, classic assumption test, regression analysis, correlation coefficient analysis, coefficient of determination analysis andhypothesis testing. The results of this study are that Discipline has a significant effect on employee performance with a regression equation $Y=15.102+0.625 X 1$, a correlation value of 0.661 means that the two variables have a strong relationship with a coefficient of determination of $43.8 \%$. Hypothesis testing obtained $t$ count $>t$ table or $(6.111>2.011)$. Thus $\mathrm{HO}$ is rejected and H1 is accepted meaning that there is a significant influence between discipline on employee performance.

Keywords: Work Discipline, Employee Productivity

\section{PENDAHULUAN}

Disiplin kerja yang dilakukan oleh seorang karyawan disuatu perusahaan merupakan salah satu bentuk bahwa perusahaan tersebut memiliki manajemen sumber daya manusia yang baik. Disiplin kerja dapat dilihat sebagai sesuatu yang besar manfaatnya, baik bagi kepentingan organisasi maupun bagi para karyawan. Menurut Hasibuan (2016:212) "mengemukakan bahwa disiplin kerja adalah kesadaran dan kesediaan seseorang mentaati semua peraturan perusahaan dan norma- norma sosial yang berlaku" Menurut Singodimedjo dalam Edy Sutrisno (2016:86), menyatakan bahwa "Disiplin adalah sikap kesediaan dan kerelaan seseorang untuk mematuhi dan menaati norma-norma peraturan yang berlaku disekitarnya". Dari pendapat di atas maka penulis dapat memahami bahwa disiplin adalah sikap atau kesediaan seseorang untuk taat dan patuh terhadap aturan yang berlaku dalam suatu organisasi.

Kinerja karyawan di PT. ISS INDONESIA akhir-akhir ini semakin menurun bila dilihat berdasarkan tingkat absensi dari karyawan yang sering alfa dengan alasan yang tidak jelas, dan terlambat masuk kerja tidak sesuai dengan aturan jam kerja. Penggunaan waktu secara efektif adalah salah satu indikator disiplin kerja, lemahnya pengawasan serta 
tidak adanya tindakan tegas terhadap kehadiran karyawan membuat karyawan menganggap hal yang wajar. Oleh karena itu perlunya untuk mengetahui pengaruh disiplin kerja terhadap kinerja karyawan. Lebih lanjut hipotesis pada penelitian ini adalah:

$\mathrm{H}_{0}=$ Diduga tidak terdapat pengaruh yang signifikan antara disiplin $(X)$ terhadap kinerja karyawan (Y) pada PT. ISS INDONESIA AREA WTC 3 SUDIRMAN.

$\mathrm{H}_{\mathrm{a}}=$ Diduga terdapat pengaruh yang signifikan antara disiplin (X) terhadap kinerja karyawan (Y) pada PT. ISS INDONESIA AREA WTC 3 SUDIRMAN.

\section{METODE}

Penelitian ini dilaksanakan di PT ISS INDONESIA di alamat yang berlokasi di WTC (World Trade Center ) 3 Jalan Jendral Sudirman, Kuningan, Kota Jakarta Selatan. Waktu Penelitian ini dilaksanakan selama 3 (tiga) bulan yang dimulai dari bulan April - Juli 2020. Menurut Sugiyono (2017:82) berpendapat "sampling jenuh adalah teknik penentuan sampel bila semua anggota populasi digunakan sebagai sampel". Dalam penelitian ini sampel yang digunakan adalah seluruh karyawan PT ISS INDONESIA WTC 3 yang berjumlah 50 karyawan. Teknik analisis data yang digunakan adalah Uji Instrumen Data (uji validitas dan uji reliabilitas), Uji Asumsi Klasik (uji normalitas, dan uji autokorelasi), dan Analisis kuantitatif (analisis regresi linier sederhana), analisis koefisien determinasi, dan uji hipotesis.

\section{HASIL PENELITIAN DAN PEMBAHASAN}

\section{Pengujian Instrumen Data}

Alat pembuktian meliputi uji validitas dan uji reliabilitas. Untuk mengolah uji validitas, peneliti menggunakan SPSS Versi 26, berikut merupakan hasil uji validitas :

Tabel 1. Hasil Uji Validitas Disiplin Kerja

\begin{tabular}{|c|l|c|c|c|}
\hline No & \multicolumn{1}{|c|}{ Kuesioner } & r-hitung & r-tabel & Keputusan \\
\hline 1 & $\begin{array}{l}\text { Karyawan yang tidak masuk kerja tanpa } \\
\text { keterangan lebih dari 3 kali akan mendapat } \\
\text { surat peringatan }\end{array}$ & 0.548 & 0,279 & Valid \\
\hline 2 & $\begin{array}{l}\text { Absensi kehadiran tercatat dengan baik oleh } \\
\text { perusahaan. }\end{array}$ & 0.389 & 0,279 & Valid \\
\hline 3 & $\begin{array}{l}\text { Karyawan selalu memberi tahu atasan jika } \\
\text { absen bekerja }\end{array}$ & 0.41 & 0,279 & Valid \\
\hline 4 & $\begin{array}{l}\text { Karyawan memiliki pemahaman yang baik } \\
\text { pada peraturan kerja }\end{array}$ & 0.422 & 0,279 & Valid \\
\hline 5 & $\begin{array}{l}\text { Karyawan yang melanggar peraturan akan } \\
\text { mendapatkan sanksi }\end{array}$ & 0.722 & 0,279 & Valid \\
\hline 6 & $\begin{array}{l}\text { Peraturan kerja dilaksanakan oleh perusahaan } \\
\text { tanpa pilih kasih }\end{array}$ & 0.564 & 0,279 & Valid \\
\hline 7 & $\begin{array}{l}\text { Karyawan selalu datang sebelum jam kerja } \\
\text { dimulai }\end{array}$ & 0.763 & 0,279 & Valid \\
\hline 8 & $\begin{array}{l}\text { Karyawan menggunakan waktu istirahat } \\
\text { dengan baik }\end{array}$ & 0.741 & 0,279 & Valid \\
\hline
\end{tabular}

Sumber : data primer diolah, 2020.

Berdasarkan data tabel di atas, variabel disiplin $\left(X_{1}\right)$ diperoleh nilai $r$ hitung $>r$ tabel $(0,279)$, dengan

demikian maka semua item kuesioner dinyatakan valid. Untuk itu kuesioner yang digunakan layak untuk diolah sebagai data penelitian. 
Tabel 2. Hasil Uji Validitas Berdasarkan Variabel Kinerja Karyawan (Y)

\begin{tabular}{|c|l|c|c|c|}
\hline No & \multicolumn{1}{|c|}{ Kuesioner } & $\mathrm{r}$ hitung & $\mathrm{r}$ tabel & Keputusan \\
\hline 1 & $\begin{array}{l}\text { Karyawan mampu mengerjakan pekerjaan sesuai } \\
\text { dengan standar yang dibuat perusahaan. }\end{array}$ & 0.534 & 0,279 & Valid \\
\hline 2 & $\begin{array}{l}\text { Karyawan mampu menguasai bidang pekerjaan } \\
\text { dengan hasil yang baik. }\end{array}$ & 0.562 & 0,279 & Valid \\
\hline 3 & $\begin{array}{l}\text { Karyawan mampu menyelesaikan pekerjaan sesuai } \\
\text { harapan perusahaan. }\end{array}$ & 0.453 & 0,279 & Valid \\
\hline 4 & $\begin{array}{l}\text { Hasil kinerja saya terkadang melebihi hasil yang telah } \\
\text { ditetapkan oleh perusahaan. }\end{array}$ & 0.382 & 0,279 & Valid \\
\hline 5 & $\begin{array}{l}\text { Tepat waktu dalam menyelesaikan pekerjaan adalah } \\
\text { kewajiban yang harus anda penuhi. }\end{array}$ & 0.459 & 0,279 & Valid \\
\hline 6 & $\begin{array}{l}\text { Keteparan waktu menjadi prioritas dalam } \\
\text { menjalankan pekerjaan }\end{array}$ & 0.458 & 0,279 & Valid \\
\hline 7 & $\begin{array}{l}\text { Kemampuan kerjasama antar karyawan yang terus } \\
\text { meningkat menandakan bahwa kinerja karyawan } \\
\text { semakin baik. }\end{array}$ & 0.726 & 0,279 & Valid \\
\hline 8 & $\begin{array}{l}\text { Saya mampu mengasati persoalan yang muncul dalam } \\
\text { pekerjaan yang saya lakukan }\end{array}$ & 0.634 & 0,279 & Valid \\
\hline 9 & $\begin{array}{l}\text { Perusahaan membayar upah sesuai dengan ketentuan } \\
\text { yang berlaku. }\end{array}$ & 0.711 & 0,279 & Valid \\
\hline 10 & $\begin{array}{l}\text { Karyawan akan mendapatkan sanksi jika mengerjakan } \\
\text { pekerjaan diluar dari standar Operasional Prosedur }\end{array}$ & 0.557 & 0,279 & Valid \\
\hline
\end{tabular}

Sumber: Data Primer diolah, 2020.

Berdasarkan data tabel di atas, variabel kinerja karyawan (Y) diperoleh nilai $\mathrm{r}$ hitung $>\mathrm{r}$ tabel $(0,279)$, dengan demikian maka semua item kuesioner dinyatakan valid. Tabel 3. Hasil Uji reliabilitas Disiplin kerja dan Kinerja

\begin{tabular}{c|r|r|r|}
\multicolumn{1}{c|}{ Variabel } & Cronbatch Alpha & Standar Cronbatch Alpha & Keputusan \\
\hline Disiplin Kerja $(\mathrm{X})$ & 0.758 & 0.6 & Reliabel \\
\hline Kinerja Karyawan $(\mathrm{Y})$ & 0.738 & 0.6 & Reliabel \\
\hline
\end{tabular}

Sumber : data primer diolah, 2020.

Berdasarkan hasil pengujian pada tabel di atas, menunjukkan bahwa variabel disiplin $(X)$ dan kinerja karyawan (Y) dinyatakan reliabel, hal itu dibuktikan dengan masing-masing variabel memiliki nilai Chronbath Alpha lebih besar dari 0,600.

\section{Pengujian Asumsi Klasik}

Pembuktian dilakukan dengan menggunakan uji normalitas dan uji autokorelitas. Untuk Uji normalitas

Untuk itu kuesioner yang digunakan layak untuk diolah sebagai data penelitian. Setelah pengujian vakiditas dilanjutkan dengan uji reliabilitas, didapatkan hasil sebagai berikut : 
Berdasarkan hasil pengujian pada tabel di atas, diperoleh nilai signifikansi $0,200>0,050)$. Dengan demikian asumsi terjadi distribusi normal. Selanjutnya uji autokorelasi

Tabel 5. Hasil Uji Autokorelasi Dengan Durbin-Watson

Model Summary

Model R R Square Adjusted R Square Std. Error of the Estimate Durbin-Watson

\begin{tabular}{lccc}
1 & $.725 \mathrm{a}$ & .526 & .506 \\
\hline & Sumber: Data Primer diolah, 2020.
\end{tabular}

Berdasarkan hasil pengujian pada tabel di atas, model regresi ini tidak ada autokorelasi, hal ini dibuktikan dengan nilai DurbinWatson sebesar 1.638 yang berada diantara interval $1.550-2.460$. untuk mengetahui ada atau tidaknya penyimpangan korelasi antar anggota sampel. Berikut hasil dari uji autokorelasi:

\section{Analisis Kuantitatif}

Pada analisis kuantitatif digunakan uji regresi linier sederhana, analisis koefisien korelasi dan analisis koefisien determinasi. Dimana uji regresi linier sederhana untuk mengetahui pengaruh seberapa besar pengaruh variabel disiplin kerja terhadap kinerja karyawan. Berikut hasil dari uji regresi sederhana :

Tabel 6. Hasil Pengujian Regresi Linier Sederhana Variabel Disiplin (1)

TTerhadap Kinerja Karyawan (Y)

Coefficients $^{\mathrm{a}}$

Unstandardized Standardized

Coefficients Coefficients

\begin{tabular}{|l|l|l|l|l|l|}
\hline Model & B & Std. Error & Beta & t & Sig. \\
\hline 1 (Constant) & 15.102 & 3.905 & & 3.867 & .000 \\
\hline Disiplin $(\mathrm{X})$ & .625 & .102 & .661 & 6.111 & .000 \\
\hline
\end{tabular}

Sumber: Data Primer diolah, 2020.

Berdasarkan hasil perhitungan regresi pada tabel di atas, maka dapat diperoleh persamaan regresi $Y=15,102$ $+0,625 X 1$. Dari persamaan di atas maka dapat disimpulkan sebagai berikut:

1. Nilai konstanta sebesar 15,102 diartikan bahwa jika variabel disiplin $(X)$ tidak ada maka telah terdapat nilai kinerja karyawan $(\mathrm{Y})$ sebesar 15,102 poin.

2. Nilai koefisien regresi disiplin (X1) sebesar 0,625 diartikan apabila Tabel 7. Hasil Analisis Koefisien Korelasi Secara Parsial Antara Disiplin Kerja terhadap kinerja
Karyawan

Correlations $^{b}$

\begin{tabular}{|c|c|c|c|}
\hline \multirow[b]{2}{*}{$\begin{array}{l}\text { Disiplin } \\
(\mathrm{X})\end{array}$} & \multicolumn{2}{|c|}{$\begin{array}{l}\text { Karyawan } \\
\text { Correlations }^{b}\end{array}$} & \\
\hline & $\begin{array}{c}\text { Kinerja } \\
\text { karyawan(Y) }\end{array}$ & & \\
\hline Disiplin & Pearson Correlation & 1 & $.661^{* *}$ \\
\hline$(\mathrm{X} 1)^{\mathrm{x}}$ & Sig. (2-tailed) & & .000 \\
\hline Kinerja & Pearson Correlation & $.661^{* *}$ & 1 \\
\hline $\begin{array}{l}\text { Karyaw } \\
\text { an }(\mathrm{Y})\end{array}$ & Sig. (2-tailed) & .000 & \\
\hline
\end{tabular}

\begin{tabular}{|c|c|c|c|}
\hline \multirow[b]{2}{*}{$\begin{array}{l}\text { Disiplin } \\
(\mathrm{X})\end{array}$} & \multicolumn{2}{|c|}{$\begin{array}{l}\text { Karyawan } \\
\text { Correlations }^{b}\end{array}$} & \\
\hline & $\begin{array}{c}\text { Kinerja } \\
\text { karyawan(Y) }\end{array}$ & & \\
\hline Disiplin & Pearson Correlation & 1 & $.661^{* *}$ \\
\hline$(\mathrm{X} 1)^{\mathrm{x}}$ & Sig. (2-tailed) & & .000 \\
\hline Kinerja & Pearson Correlation & $.661^{* *}$ & 1 \\
\hline $\begin{array}{l}\text { Karyaw } \\
\text { an }(\mathrm{Y})\end{array}$ & Sig. (2-tailed) & .000 & \\
\hline
\end{tabular}

Sumber: Data Primer diolah, 2020. konstanta tetap, maka setiap disiplin $(X)$ akan mengakibatkan terjadinya perubahan pada kinerja karyawan (Y) sebesar 0,625 point.

Selanjutnya dilakukan analisis koefisien korelasi, dimana analisis koefisien korelasi dimaksudkan untuk mengetahui tingkat kekuatan hubungan antara variabel independen terhadap variabel dependen. Berikut hasil dari analisis koefisien korelasi : perubahan 1 unit pada variabel 
Berdasarkan hasil pengujian pada tabel di atas, diperoleh nilai Koefisien korelasi sebesar 0,661 artinya kedua variabel memiliki tingkat hubungan yang kuat. Lebih lanjut dilakukan analisis koefisien determinasi dimana analisis koefisien determinasi dimaksudkan untuk mengetahui

Tabel 8. Hasil Analisis Koefisien Determinasi Secara Parsial Antara Disiplin (X1) Terhadap Kinerja Karyawan $(\mathrm{Y})$

Model Summary

Adjusted R Std. Error of the

\begin{tabular}{lcccc} 
Model R & \multicolumn{2}{c}{ R SquareSquare } & Estimate & \\
\hline 1 & a & .438 & .426 & 2.873 \\
\hline
\end{tabular}

Sumber: Data Primer diolah, 2020.

Berdasarkan pada hasil

pengujian pada tabel di atas, diperoleh

nilai Koefisien determinasi sebesar 0,438 maka dapat disimpulkan bahwa variabel disiplin berpengaruh terhadap variabel kinerja karyawan sebesar $43,8 \%$ sedangkan sisanya sebesar $56,2 \%$ dipengaruhi oleh faktor lain. persentase kekuatan hubungan antara variabel independen terhadap variabel dependen baik secara parsial maupun simultan.

Berikut ini hasil perhitungan koefisien determinasi yang diolah dengan program SPSS Versi 26, sebagai berikut:
4. Pengujian Hipotesis.

Pengujian Hipotesis Secara Parsial (Uji t). Dalam penelitian ini digunakan kriteria signifikansi 5\% $(0,05)$ dengan membandingkan antara nilai $\mathrm{t}$ hitung dengan $\mathrm{t}$ tabel. Adapun hasil pengolahan data menggunakan program SPSS Versi 26, dengan hasil sebagai berikut:

Tabel 9. Hasil Uji Hipotesis (Uji t) Variabel Disiplin (X) Terhadap Kinerja Karyawan (Y)

\begin{tabular}{|c|c|c|c|c|c|}
\hline $\begin{array}{l}\text { Uns } \\
\text { Coe }\end{array}$ & $\begin{array}{l}\text { andardi } \\
\text { ficiets }\end{array}$ & ized & $\begin{array}{l}\text { Standardized } \\
\text { Coefficients }\end{array}$ & $\mathrm{d}$ & Sig \\
\hline Model & B & Std. Error & Beta & & \\
\hline 1 (Constant) & 15.102 & 3.905 & & 3.867 & .000 \\
\hline Disiplin $(X)$ & .625 & .102 & 661 & 16.111 & .000 \\
\hline
\end{tabular}

Sumber: Data Primer diolah, 2020.

Berdasarkan pada hasil pengujian pada tabel di atas diperoleh nilai $\mathrm{t}$ hitung $>\mathrm{t}$ tabel atau $(6,111>2,011) \mathrm{Hal}$ tersebut juga diperkuat dengan nilai $\rho$ value < Sig.0,05 atau $(0,000<0,05)$. Dengan demikian maka $\mathrm{H}_{0}$ ditolak dan $\mathrm{H}_{\mathrm{a}}$ diterima, hal ini menunjukkan bahwa terdapat pengaruh yang signifikan secara parsial antara disiplin terhadap kinerja karyawan pada PT. ISS INDONESIA AREA WTC 3 SUDIRMAN.

\section{KESIMPULAN}

Berdasarkan hasil analisis serta pembahasan didapatkan kesimpulan bahwa Disiplin berpengaruh signifikan terhadap kinerja karyawan dengan persamaan regresi $Y=15,102+0,625 X 1$, nilai korelasi sebesar 0,661 artinya kedua variabel memiliki tingkat hubungan yang kuat dengan koefisien determinasi sebesar $43,8 \%$. Uji hipotesis diperoleh $\mathrm{t}$ hitung $>\mathrm{t}$ tabel atau $(6,111>2,011)$. Dengan demikian H01 ditolak dan Ha1 diterima artinya terdapat pengaruh signifikan antara disiplin terhadap kinerja karyawan.

\section{SARAN}

Pada penelitian ini disarankan untuk karyawan yang tidak masuk kerja tanpa keterangan lebih dari 3 kali akan mendapat surat peringatan yang selama ini hanya mendapatkan surat peringatan untuk lebih baik lagi perusahaan harus tegas kepada karyawan yang masih mengabaikan peraturan-peraturan yang sudah ditetapkan oleh perusahaan. Karena karaywan merupakan asset penting bagi kemajuan perusahaan. 
DAFTAR PUSTAKA

Ambar,T, Rosidah, 2018, Manajemen Sumber Daya Manusia, Yogyakarta : Penerbit Gava Media

Edi Sutrisno, 2019, Manajemen Sumber Daya Manusia, Jakarta : Prenamedia Group

Edison Emron, Anwar dan Komariyah, 2017, Manajemen Sumber Daya Manusia Strategi Perubahan Dalam Rangka Meningkatkan Kinerja Pegawai danOrganisasi, Bandung : Alfabeta

Ghozali, Imam, 2017, Aplikasi Analisis Multivariate Dengan Program SPSS, Edisi Kelima, Semarang: Badan Penerbit Undip.

Hasibuan Malayu SP, 2019, Manajemen Sumber Daya Manusia, Edisi Revisi,Jakarta : PT Bumi Aksara

Kasmir, 2015, Manajemen Sumber Daya Manusia, Jakarta : PT Raja Grafindo Persada.

Kustini, E., et al. (2021). Pengaruh Keterampilan Kerja Dan Lingkungan Kerja Terhadap Kinerja Karyawan Pada PT. Garuda Daya Pratama Sejahtera (Garuda Indonesia Group). Jurnal Ilmiah PERKUSI, 1(3), 305-314.
Nurjaya, N., et al. (2020). Edupreneurship management in shaping the nation's character. Jurnal Konseling dan Pendidikan, 8(3), 198-206.

Sedarmayanti, 2016 , Manajemen Sumber Daya Manusia, Reformasi Birokrasi dan Manajemen Pegawai Negeri Sipil, Cetakan Kelima, Bandung: PT Refika Aditama.

Sedarmayanti, 2018, Sumber Daya Manusia dan Produktivitas Kerja, CV, Mandar Maju, Bandung.

Sugiyono, 2017, Metode Penelitian Administrasi : dilengkapi dengan Metode $R \mathcal{E}$ D, Bandung: Alfabeta.

Sutrisno, Edi, 2016, Manajemen Sumber Daya Manusia, Jakarta: Prenadamedia Group.

Sutrisno, Edi, 2016, Sumber Daya Manusia, Surabaya: PT.Gramedia.

Suwanto, S., et al. (2021). Pengaruh Motivasi Dan Pengalaman Kerja Terhadap Produktivitas Karyawan Pada Happy Restaurant Di Bandung. Jurnal Ekonomi Efektif, 3(4), 546-554. 